\title{
DOES EVIDENCE CHALLENGE THE DSGE MODEL?
}

\author{
Tanya ARAÚJO ${ }^{1}$, Sofia TERLICA ${ }^{3}$, Samuel ELEUTÉRIO ${ }^{2}$, Francisco LOUÇÃ ${ }^{1}$ \\ ${ }^{1}$ ISEG, University of Lisbon and UECE, R. Miguel Lupi 20, 1249-078 Lisboa, Portugal \\ ${ }^{2}$ Instituto Superior Técnico, University of Lisbon Av. Rovisco Pais 1049-001 Lisboa \\ ${ }^{3}$ Banco de Portugal
}

\begin{abstract}
DSGE are for a time the favorite models in the simulation of monetary policies at the central banks. Two of its basic assumptions are discussed in this paper: (a) the absence of endogenous nonlinearities and the exogenous nature of shocks and $(b)$ the persistence of or the return to equilibrium after a shock, or the absence of dynamics. Our analysis of complex financial markets, using historical data of $S \& P 500$, suggests otherwise that financial regimes endogenously change and that equilibrium is an artifact.
\end{abstract}

\section{KEYWORDS}

Market Crises, Stochastic Geometry, Efficient Market Hypothesis, General Equilibrium, Financial Markets.

\section{JEL Codes}

C19, C49, C69.

\section{INTRODUCTION}

A founder of modern approach to General Equilibrium economics, Kenneth Arrow, suggested almost twenty years ago that the standard models were deficient and falsified by the real dynamics of several markets, such as the labor market and the financial market. In particular, he emphasized the "excess volatility of share, oil, metal and other mineral prices, which is hard to explain as movements in expected discounted values of future prices" and "as for share prices, there are a number of other difficulties in reconciling the actual course of prices with any form of rational expectations. In particular, the observed data on neither the excess return on equities compared with bonds nor the volume of trading on securities (and other financial markets) can be explained in these terms" (Arrow, 1994). This paper addresses these difficulties considering the contemporaneous standard approach used by central banks to model macroeconomics, which combines the real business cycle theories with the Keynesianism view of price rigidities, resulting in the New Keynesian Perspective (Clarida et al, 1999) or New Neoclassical synthesis (Goodfriend and King, 1997).

Within this approach, Dynamic Stochastic General Equilibrium (DSGE) models present simple stochastic processes and impulse reaction functions to some shocks. They became popular among academics but particularly among researchers at central banks because monetary policy decisions 
appear in the DSGE as instruments, in contrast with classical models were monetary policy is assumed to be of no relevance to real activity fluctuations.

The importance of DSGE models has been widespread among decision markers who rely on this type of models for monetary and fiscal guidance. Although DSGE models have been developed with important realistic features compared to Keynesian models or to neoclassical general equilibrium models (as it is the example of sticky prices, monopolistic competition in the goods market, intertemporal budget constrains) there are several assumptions that are far from reality and bear important implications (Leijonhufvud, 2009; De Grawe, 2010).

In this paper we challenge two of the DSGE assumptions, (a) the absence of endogenous nonlinearities and (b) the persistence of equilibrium or the absence of dynamics, and argue that evidence falsifies both.

\section{The DSGE model}

In DSGE models shocks are exogenous (Leijonhufvud, 2009; De Grawe, 2010). The model is composed by a state of functions working in a steady-state growth, and conditions are imposed to the coefficients for determinacy of equilibrium. Besides the equilibrium process, some shocks might be introduced and the model is deemed to absorb the shocks until the equilibrium path is recovered in the former way or in a different but still in an equilibrium path. Shocks are presented in the most equations of the model, because it is the element that brings dynamic to the system. One of the shocks is the cost-push, which shifts the aggregate-supply relation, and affects consumers' utility function. The typical formalization of the aggregate-supply relation in each period is (Woodford, 2003):

$$
\prod(t)=k X(t)+b E(t) \prod(t-1)+\mathrm{u}(\mathrm{t})
$$

where $u(t)$ is an exogenous cost-push shock.

This is an unanticipated shock, but in any case, the economy's state contingent evolution must satisfy the condition that allows for a determinate equilibrium. The model does not analyze the different nature of the shocks, but the different reactions of it in the case of optimal policy commitment or in the case of discretionary optimization, resulting from the fact that in the first the model is history dependent while in the second it is forward looking.

The absence of financial markets dynamics results from the fact, as Solow (2008) points out, that the same model is valid in different time horizons, as there is no distinction between short run and long run. In fact, besides from the exogenous shocks, the model does not take into account any turmoil. The model assumes data as a result of a data generating process, i.e. it is assumed that empirical data is the result of the model and thus disturbances are a random walk. This confusion between the theoretical representation and the empirical variables contributes to the absence of empirical dynamics with no regret.

In the presence of the financial turmoil in 2007, some models tried to circumvent the lack of dynamics and increased the role given to financial variables. For instance, stock prices were, in some cases, introduced as an exogenous cause of friction to the monetary policy objective. Christiano et al (2011) deal with the impact of stock prices in inflation, and conclude that if inflation is low during stock market booms and if the interest rate rule is too narrowly focused on inflation it will destabilize asset markets and broader economy. This is in line with previous literature, as in Bernanke and Gertler $(1999,2001)$. However in Bernanke and Gertler stock prices 
are observed as the result of monetary policy and an undesirable source of inflation. Using data from the US and Japan in a standard New Keynesian (NK) model, the authors conclude that inflation targeting may destabilize a boom: monetary policy is in part responsible for at least some booms by responding to the fall in inflation with interest rate cuts. The robustness of results was tested with a medium-size NK model that incorporates capital and various frictions, according to the business cycle data. In the same line, the model by Gust and López-Salido (2009) is consistent with the evidence that unanticipated changes in monetary policy have important effects on equity prices through changes in risk. In this model, households rebalance their portfolio according to the economy's risk, and because monetary policy affects equity premium it affects household rebalancing and consumption and investment decisions.

Based on a demand approach to the stock prices affecting real economy, Castelnuovo and Nisticò (2009) have shown evidence of a significant role of stock prices on business cycle. In this standard DSGE model, a stock-price gap is built to measure the financial slack in each period. It is calculated as the percent deviation of the real stock-price index from its frictionless level relevant for monetary policy, the latter being consistent with equilibrium with no dynamic distortions. As it captures the cyclical nature of stock prices, and being statistical significant, it is an important variable in the monetary policy decision. In this model, stock prices induced by a financial shock affect the whole economy, although the effect on the output gap is not straightforward. In the case of a stock-price boom, there is a positive effect through the wealth effect on consumption but also an indirect effect on the induced variations in the interest rate. This indirect effect has an opposite direction, as the effect of rising interest rates is contractionary on current output due to consumers' intertemporal substitution effect. The net effect depends on the relative strength of the two, although empirically it turns to be that the direct effect dominates. The output gap tends to be positively influenced by a financial shock, although moderately. In Nisticò $(2011,2012)$ the effect of stock price dynamics in wealth is seen as an additional dynamic distortion. It concludes that some fluctuations in output and inflation may be optimal as they reduce volatility of financial wealth.

This is in line with central banks concerns on financial stability, and increasingly authors have been considering financial stability as an independent target of a welfare-maximizing central bank. The link between financial assets and monetary policy has been more explored since the financial market distress in 2001. Some results reveal that monetary policy might be improved, in the sense of approaching to the optimal, if macroprudential concerns are taken into account. In this line, some studies introduce financial asset prices dynamics, and as they turn to be relevant it shows that they are not just relevant as affecting consumer prices, but they have an active role in determining business cycle. Lambertini et al (2011) developed a DSGE model where the central bank has macroprudential concerns, testing if the monetary authority should react to housing prices or credit growth movements to avoid boom-bust cycles in the financial market. They conclude that a higher level of welfare might be reached if monetary policy responds to financial conditions.

Also in line with financial distress has been the concern over international financial integration. Milani (2011) suggests a bilateral financial linkage analysis that exposed important cross-border wealth effects. The empirical study revealed that Ireland, and at a lesser extent Austria, revealed a cross-border wealth effect: changes in international stock prices (US and UK stocks) have an important impact on the economies' aggregate consumption and real activity.

These developments stress the importance to take into account the dynamics of financial variables. The general equilibrium path might be affected by the stock prices dynamics, but DSGE models do not consider the endogeneity of its dynamics. Our results suggest otherwise. 


\section{The model}

The strategy of measurement of the space of the financial market is simply stated in the following terms. From the set of returns of the stocks and their historical data of returns over the time interval, and using an appropriate metric (Mantegna, 1999, 2000), we compute the matrix of distances between the stocks. Considering the returns for each stock,

$$
r(k)=\log \left(p_{t}(k)\right)-\log \left(p_{t-1}(k)\right)
$$

a normalized vector

$$
\vec{\rho}(k)=\frac{\vec{r}(k)-\langle\vec{r}(k)\rangle}{\sqrt{n\left(\left\langle\overrightarrow{r^{2}}(k)\right\rangle-\langle\vec{r}(k)\rangle^{2}\right)}}
$$

is defined, where $n$ is the number of components (number of time labels) in the vector $\vec{\rho}(k)$. With this vector one defines the distance between the stocks $k$ and $l$ by the Euclidian distance of the normalized vectors.

$$
d_{i j}=\sqrt{2\left(1-C_{i j}\right)}=\|\vec{\rho}(k)-\vec{\rho}(l)\|
$$

with $C_{i j}$ being the correlation coefficient of the returns $r(i), r(j)$.

As the distance is properly defined according to the due metric axioms, it is possible to obtain, from the matrix of distances, the coordinates for the stocks in a Euclidean space of dimension smaller than N. The standard analysis of reduction of the coordinates is applied to the center of mass and the eigenvectors of the inertial tensor are then computed.

The same technique is also applied to surrogate (time-permuted and random) data, namely to data obtained by independent time permutation for each stock, and these eigenvalues are compared with those obtained from actual data in order to identify the characteristic directions for which the eigenvalues are significantly different. They define a reduced subspace of dimension $\mathrm{f}$, which carries the systematic information related to the market correlation structure.

This corresponds to the identification of empirically constructed variables that drive the market and, in this framework, the number of surviving eigenvalues is the effective characteristic dimension of this economic space (f). This procedure is the key for the following method, since it allows for the consideration of populations of hundreds of stocks, given that only a very small number of coordinates describing their distances is used in the computation of our measures of the multivariate space.

\section{The new axes}

After calculating the one-day returns for each of the companies and taking a time interval $\Delta T$, the vectors $\mathrm{r}(\mathrm{t})$ are defined with coordinates corresponding to the returns of each company in each day $\mathrm{t}$ of the chosen interval $\Delta t$.

$$
\vec{\rho}(t)=\frac{\vec{r}(t)-\langle\vec{r}(t)\rangle}{\sqrt{n\left(\left\langle\overrightarrow{r^{2}}(t)\right\rangle-\langle\vec{r}(t)\rangle^{2}\right)}}
$$


where $\mathrm{n}$ corresponds to the length of the vectors $\mathrm{r}(\mathrm{t})$, that is, to the number of companies.

Then, the distance between day $\mathrm{t} \square$ and $\mathrm{t} \square$ is computed as

$$
d_{t 1, t 2}=\sqrt{2\left(1-C_{t 1, t 2}\right)}=\left\|\vec{\rho}\left(t_{1}\right)-\vec{\rho}\left(t_{2}\right)\right\|
$$

$C_{t 1, t 2}$ being the correlation coefficient between the daily returns in $\mathrm{t} \square$ and $\mathrm{t} \square$, using a time window of $\mathrm{n}$ companies.

In so doing, the difference from the original method is the exchange (switching) of the space and time axes. As a consequence, each point in $\mathrm{R}^{\wedge}\{\mathrm{t}-1\}$ now represents a position in the set of companies in each of the days of the chosen time interval.

One can then follow the evolution of the market over time and investigate whether there are important variations in the geometric representation of the days of crisis or its predecessors.

The points in the cloud no longer represent individual companies but each of the days in the chosen interval.

In order to quantify the extent of the flights in each market space, we measure its corresponding Spread as the difference between the maximal and the minimal distance in the 3-dimensional space:

$$
\text { Spread }=\max \left\{d\left(t_{i}\right),\left(t_{j}\right)-\min \left(d\left(t_{i}\right),\left(t_{j}\right)\right\}\right.
$$

This method allows for a description and measurement of the dynamics of the market in the different periods of time we consider.

\section{Preliminary results}

Figure 1 shows the market space obtained for March and October 2006, two periods of business as usual. In both cases the flights away from the core are hardly noticeable, being the corresponding spreads are 5.4 and 6, respectively. This is used to compare the periods of normal trade with those of crashes and large perturbations in the stock market.

\section{Figure 1 Hardly noticeable flights: Mar.2006 and Oct.2006.}
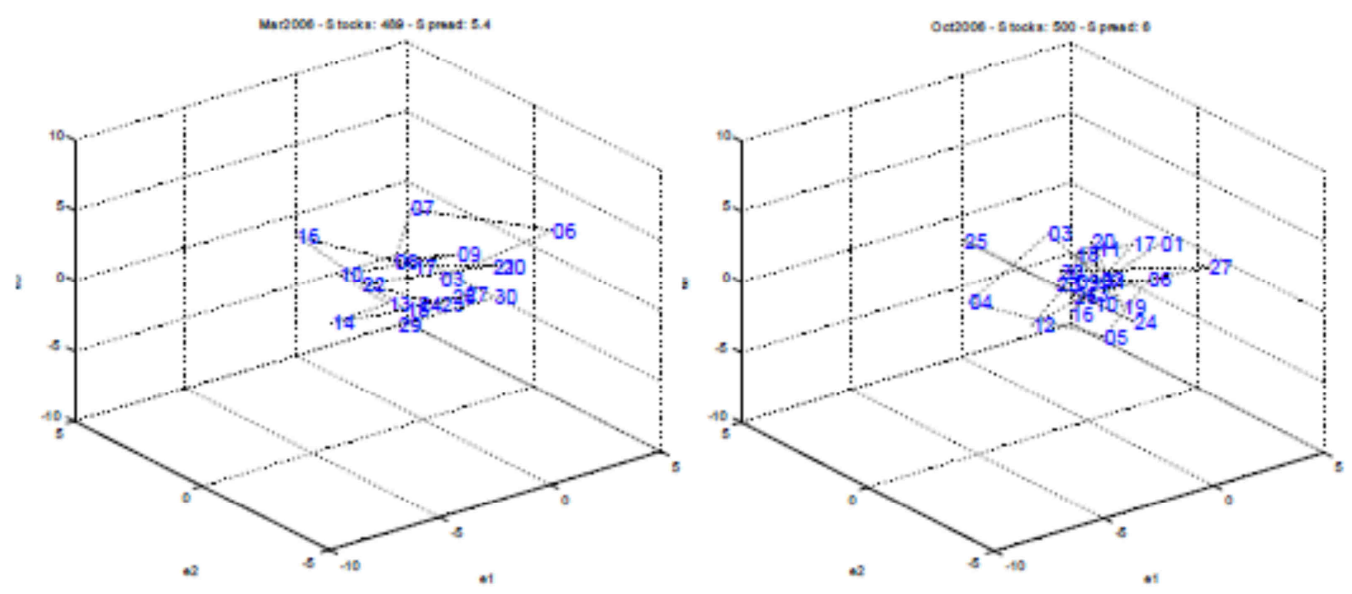
Instead, the first plot in Figure 2 shows the geometrical spaces built from daily data of September, 2008. In this case the flights away from the central core of data are more prominent and involve a greater number of days around the most critical days. As a consequence, the value of Spread is larger than in the previous example of business as usual periods, as expected.

\section{Figure 2 More prominent flights in Sep. 2008 and Nov. 2011.}
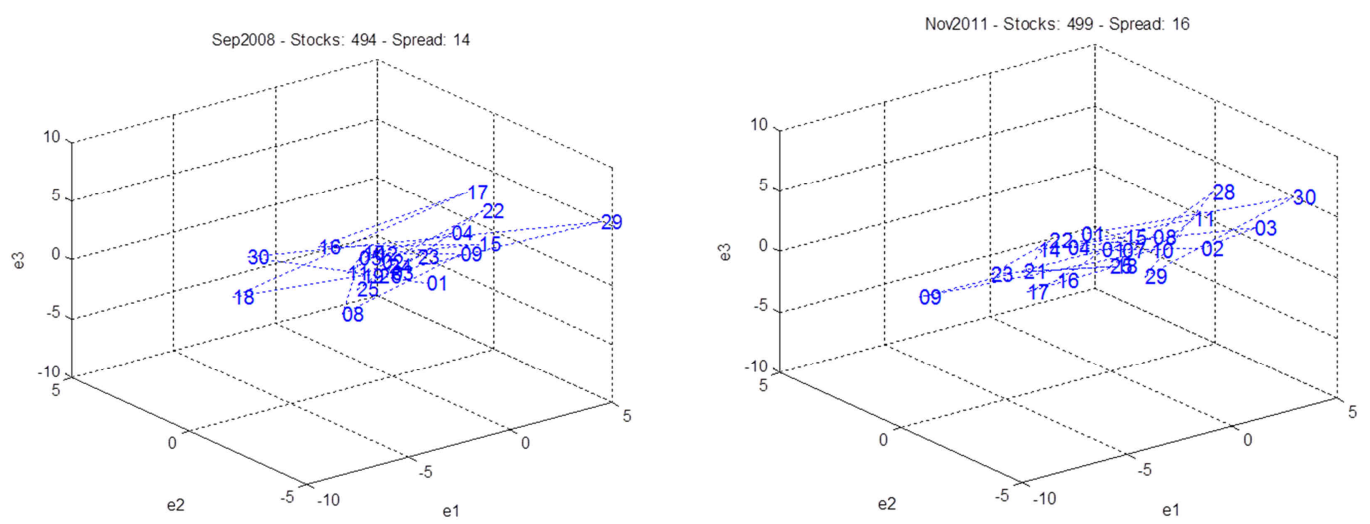

A similar result can be observed in the second plot of Figure 2, where the 22 business days of November 2011 were considered to built the geometrical space. Being more prominent, those geometrical spaces display high Spreads values of 14 and 16, respectively.

The plot in Figure 3 - showing the geometrical space built from a 22-days window around the first Black Monday, 1987 - shows that he bulk of the data consists of a central core of small fluctuations with a few large flights away from this center. This is the typical description of events in the case of large crash. These few large flights correspond precisely to the day of the crisis, one day after and one day before.

Figure 3 The large flights on the 1st Black Monday.

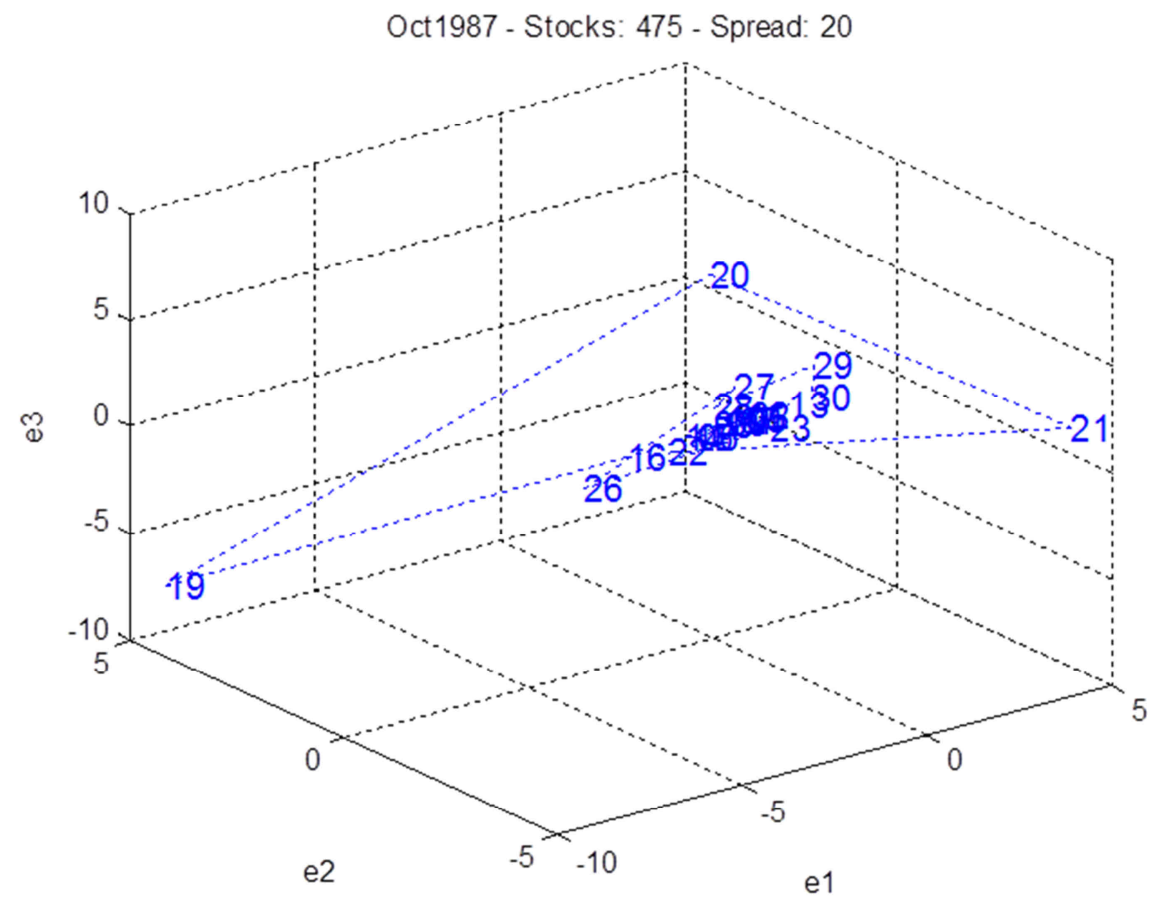


Figure 4 Big flights in October, 1989.

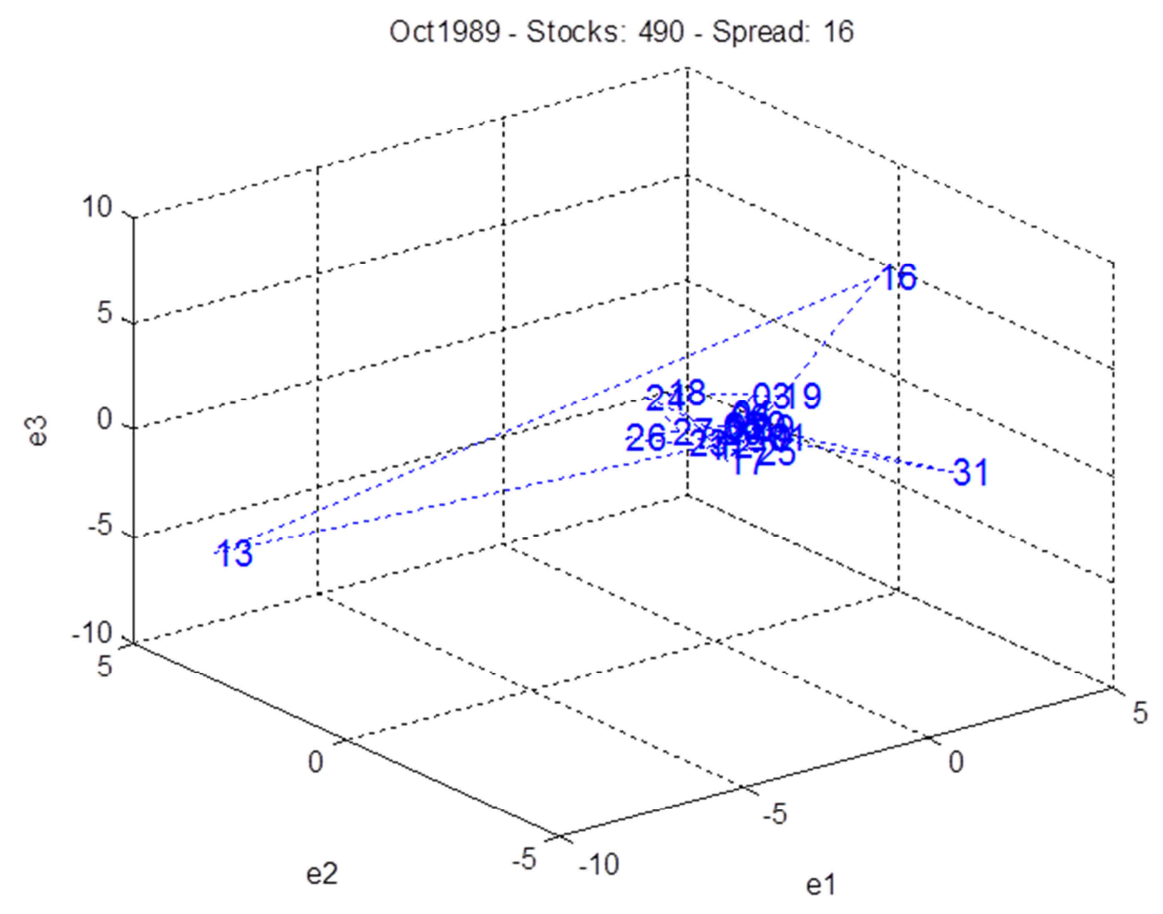

The Spread of the market space obtained in this example reaches the high value of 20, emphasizing how distances among days expand in periods of crash and turbulence.

A result similar to the one presented in Figure 3 can be observed in the plot of Figure 4, where the 22 days around the October 13, 1989 (when the US stock market fell almost 7\%) were considered in the building of the geometrical space. In this example, besides the critical days (13 and 16) the flights away from the central core of data also involve a day (31) far from the epicenter of the crisis. The corresponding Spread value is 16 .

\section{A measurement of regime changes}

In this section, we add a second dimension to this discussion of the assumptions of DSGE, considering now its statement on the persistence of or the return to equilibrium after a shock, or the absence of dynamics. Although evidence from the long series describing the financial markets is quite well known, for the purpose of this argument we simply evoke the measurement of the long term dynamics.

In that sense and based on the previously outlined definitions, we state $\mathrm{S}$ as:

$$
S_{t}=\sum_{k} \lambda t(i) / \lambda^{*} t(i)
$$

Where $\lambda t(i)$ are the largest $\mathrm{d}$ eigenvalues of the market space and $\lambda^{*} t(i)$ are the largest $\mathrm{d}$ eigenvalues obtained from surrogate data, namely from data obtained by independent time permutation of each stock. In computing $\mathrm{S}$, at a given time $\mathrm{t}$, both $\lambda t(i)$ and $\lambda^{*} t(i)$ are obtained over the same time window and for the same set of stocks.

$\mathrm{S}$ is therefore a measure of the aggregate dynamics of the market. For a long term perspective, the plot presented in Fig. 5 summarizes our findings on the evolution of the $S$. 


\section{Figure 5 The Structure index $\mathbf{S}$.}

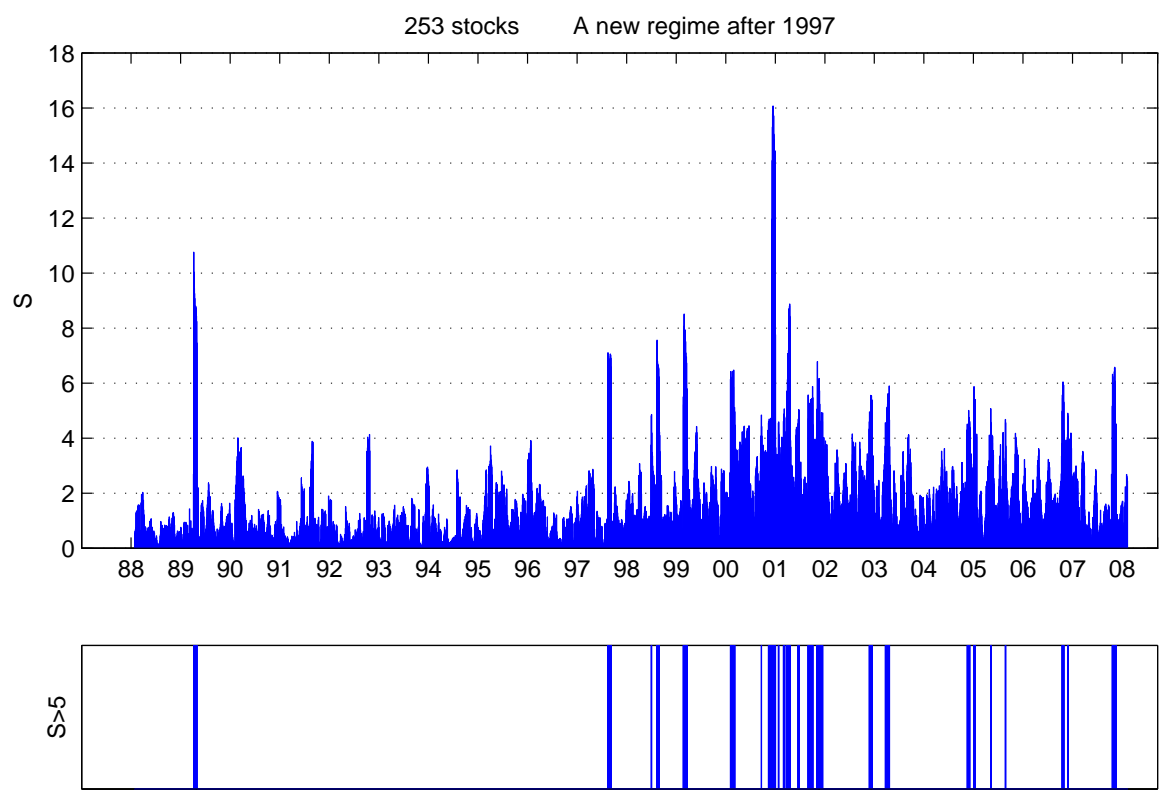

The graph also indicates those crashes that imply an S larger than 5. This seismography highlights how a new regime emerges after 1997, with larger current values of $\mathrm{S}$ and more frequent crash episodes. This confirms the larger consensus in the literature about the changes of the stock market through time.

\section{CONCLUSION}

Two of the core assumptions of DSGE were scrutinized in this paper: the assumption of exogeneity of the shocks, and absence of endogenous perturbations, and the assumption of a return to equilibrium after the dampening of the effect of the shock. Confronting such hypotheses with the real dynamics of the financial market as described by the historical series of the S\&P500, we find evidence for rejecting both.

A stochastic geometry technique is used to describe the pattern of change through different periods of time. We found that in normal periods of trade the geometric object formed by the distances among the firms and their time patterns is clustered and the dispersion is very limited, unlike what happens in periods of turmoil - a large spread is registered then. We measure this spread for several periods of crashes and interpret these perturbations as part of the financial process itself, from the action of the agents and their decisions.

Furthermore, we found that regime changes may emerge as the market is organized after the shocks. This obviously the case of the impact of modifications of the global market and the regulation procedures since the early 1980s. In both cases, we find evidence to challenge the standard assumptions of the sophisticated DSGE models.

\section{ACKNOWLEDGEMENT}

Financial support from national funds by FCT (Fundação para a Ciência e a Tecnologia). This article is part of the Strategic Project: PEst-OE/EGE/UI0436/2011. 


\section{REFERENCES}

AHREND, R., COURNÈDE, B., PRICE, R. (2008). Monetary Policy, Market Excessess and Financial Turmoil. OECD Economics Department, Working Papers 597, OECD Publishing. Doi: $10.1787 / 244200148201$.

ARAÚJO, T. and LOUÇÃ, F. (2007). The Geometry of Crashes - A Measure of the Dynamics of Stock Market Crises. Quantitative Finance 7, 63-74.

ARAÚJO, T. and LOUÇÃ, F. (2008). The Seismography of Crashes in Financial Markets. Physics Letters A, 372, 429-434.

ARROW, K. (1994). Problems Mount in Application of Free Market Economic Theory. Guardian.

BELKE, A. and KLOSE, J. (2010). How do the ECB and the Fed react to financial market uncertainty? The Taylor rule in times of crisis. Discussion Papers, German Institute for Economic Research, 1-29.

BERNANKE, B. S. and GERTLER, M. (1999). Monetary policy and asset prices volatility. Federal Reserve Bank of Kansas City Economic Review, Fourth Quarter, 84, 17-51.

BERNANKE, B. S. and GERTLER, M. (2001). Should central banks respond to movements in asset prices? American Economic Review, Papers and Proceedings, 91, 253-257.

BEZEMER, D. (2011). Causes of Financial Instability: Don't forget finance. Working paper No 665, Levy Economics Institute of Bard College, 1-27.

BIETA, V., MILDE, H. and WEBER, N. (2010). A flaw in the mode that defines how the world works. Policy Research Working Paper 5498, The World Bank, 1-13.

BOMFIM, A. (2001). Measuring Equilibrium Real Interest Rates: What can we learn from yields on indexed bonds? Federal Reserve Board, 1-25.

BORDO, M.D., DUEKER, M. J. and WHEELOCK, D.C. (2008). Inflation Monetary Policy and Stock Market Conditions. NBER Working Paper 14019, 1-30.

CASTELNUOVO, E. and NISTICÒ, S. (2009). Stock market conditions and monetary policy in a DSGE model for the US. Journal of Economic Dynamics and Control, 9, 1700-1731.

CHALLE, E. and GIANNITSAROU, C. (2008). Stock prices and monetary policy shocks: a general equilibrium approach. Ecole Polytechnique and University of Cambridge, mimeo.

CHRISTIANO, L., ILUT, C., MOTTO, R. and ROSTAGNO, M. (2011). Monetary policy and stock market booms. Working paper series, Banco central de reserva del Perú, 1-48.

CLARIDA, R., GALI, J. and GERTLER, M. (1999). The Science of Monetary Policy: A New Keynesian Perspective. Journal of Economic Literature, Vol. XXXVII, 1661-1707.

CUARESMA, J.C. and GNAN, E. (2008). Four monetary policy strategies in comparison: how to deal with financial instability? Monetary policy and Economics, 3, 65-102.

De GRAWE, P. (2010). The scientific foundation of dynamic stochastic general equilibrium (DSGE) models. Public Choice 144, 413-443.

GOODFRIEND, M. and KING, R. (1997). The new neoclassical synthesis and the role of monetary policy. NBER Macroeconomics Annual, 12, 231-296.

GUST, C. and LÓPEZ-SALIDO, D. (2009). Portfolio inertia and the equity premium. International Finance, Discussion Papers 984, Bank of Governors of the Federal Reserve System, 1-34.

LAMBERTINI, L., MENDICINO, C. and PUNZI, M.T. (2011). Leaning against boom-bust cycles in credit and housing prices. CeLeg Working paper, Center for Labor and Economic Growth, 4, 1-29.

LEIJONHUFVUD, A. (2009). Macroeconomics and the crisis: a personal appraisal. Centre for Economic Policy Research, Policy Insight, 41, 1-7.

MILANI, F. (2011). The impact of foreign stock markets on macroeconomic dynamics in open economies: a structural estimation. Journal of International Money and finance, Elsevier, 30, 111-129.

ROTEMBERG, J. and WOODFORD, M. (1997). An Optimization-based econometric framework for the evaluation of monetary policy. NBER Macroeconomics Annual, 12 , 297-346. 
SAMUELSON, P. (1965). Proof that Properly Anticipated Prices Fluctuate Randomly. Industrial Management Review, 6, 41-49.

WOODFORD, M. (2003). Interest and Prices: Foundations of a theory of monetary policy. Princeton University Press. 